\title{
Sistem Pendukung Keputusan Rekomendasi Penerima Bantuan Siswa Miskin Menggunakan Metode Simple Additive Weighting (Saw)
}

\author{
Muh. Burhanudin ${ }^{1}$,FX. Ferdinandus ${ }^{2}$, Muhaji Bayu ${ }^{3}$ \\ ${ }^{1}$ Sekolah Tinggi Teknologi Cahaya Surya Kediri \\ ${ }^{2}$ Sekolah Tinggi Teknik Surabaya \\ ${ }^{3}$ Sekolah Tinggi Teknologi Cahaya Surya Kediri \\ E-mail:burhanyes7@gmail.com,ferdi@stts.edu,muhajibayu_stt@cahayasurya.ac.id
}

\begin{abstract}
Abstrak
Tidak sedikit masyarakat Indonesia khususnya di Kota Kediri yang tidak bisa melanjutkan pendidikan sampai jenjang perguruan tinggi karena keterbatasan biaya. Oleh sebab itu, peran pemerintah pusat dalam mengatasi permasalahan ini adalah dengan diberikan Bantuan Siswa Miskin atau BSM. BSM adalah bantuan dari pemerintah berupa sejumlah uang tunai yang diberikan secara langsung kepada siswa sesuai criteria yang telah ditetapkan. Alasan lain bantuan ini diberikan pemerintah adalah untuk kompensasi atas kenaikan harga BBM (Bahan Bakar Minyak). Perangkingan siswa penerima bantuan siswa miskin. Metode yang digunakan dalam perhitungan adalah Simple Additive Weighting perhitungan manual dan perhitungan sistem menunjukkan nilai yang sama. Metode Simple Additive Weighting dipilih karena mampu menyeleksi alternative terbaik dari sejumlah alternatif, dalam hal ini alternative yang dimaksudkan yaitu yang berhak menerima BSM berdasrkan criteria-kriteria yang telah ditentukan. Penelitian dilakukan dengan mencari nilai bobot untuk setiap atribut, kemudian membuat rangking yang akan menentukan alternative yang optimal, yaitu penerima BSM. Sistem ini dapat menjadi alat bantu kerja tim penyeleksi bantuan dalam melakukan penyeleksian. Telah diimplementasikan sistem pendukung keputusan penerima bantuan siswa miskin dengan menggunakan Simple Additive Weighting (SAW) di SMK Plus Darus Salam Kediri. Aplikasi SPK yang dibuat dapat memberikan solusi terbaik dalam penentuan rekomendasi untuk mendukung keputusan penerima bantuan siswa miskin.
\end{abstract}

Kata Kunci : Sistem Pendukung, BSM, Simple Additive Weighting

\section{Pendahuluan}

\subsection{Latar Belakang Masalah}

Pendidikan merupakan suatu kebutuhan primer yang sejak dini hingga dewasa haruslah dirasakan oleh seluruh masyarakat. Namun ternyata masih banyak masyarakat yang dari kalangan menengah kebawah yang tidak mampu untuk membiayai pendidikan putra-putrinya walau sampai 9 tahun saja. Berdasarkan peraturan Pemerintah No. 32 tahun 2013 tentang perubahan atas Peraturan Pemerintahan No. 19 tahun 2005 tentang Standar Nasional Pendidikan, pada Pasal 67 yang ayat (1a) yang berisi "Ujian Nasional untuk satuan pendidikan jalur formal pendidikan dasar sebagaimana dimaksud pada ayat (1) dikecualikan untuk SD/MI/SDLB. Pemberian beasiswa merupakan program Perguruan Tinggi yang dilakukan untuk memberi penghargaan terhadap mahasiswa yang dianggap mampu mengikuti peraturan dengan tepat. Masih banyak pula siswa yang berasal dari kalangan masyarakat yang kurang mampu/menengah kebawah yang tidak dapat menyekolahkan putra-putrinya, maka dari itu diadakan Program Bantuan Siswa Miskin (BSM). Pengolahan dana dan data Bantuan Siswa Miskin yang ada pada SMK Plus Da- 
rus Salam saat ini masih menggunakan sistem yang konvensional atau belum adanya metode yang dapat membantu untuk menentukan siswa yang benar - benar berhak mendapatkan. Penentuan penerima dana bantuan siswa miskin dengan cara konvensional ini dapat mengakibatkan kesalahan dalam proses penyeleksian, sehingga kriteria penilaian siswa miskin yang telah ditetapkan itu sendiri tidak terealisasikan, hal ini diakibatkan karena sulitnya pengelolaan data dengan sistem yang ada. Berdasarkan permasalahan di atas agar pemilihan penerima bantuan siswa miskin tepat sasaran maka dapat diusulkan suatu rancangan sistem informasi pengambilan keputusan menggunakan metode Simple Additive Weighting (SAW) dengan judul "SISTEM PENDUKUNG KEPUTUSAN REKOMENDASI PENERIMA BANTUAN SISWA MISKIN MENGGUNAKAN METODE SIMPLE ADDITIVE WEIGHTING (SAW)”.

\section{Landasan Teori}

\subsection{Bantuan Siswa Miskin}

Bantuan Siswa Miskin (BSM) adalah bantuan dari pemerintah berupa jumlah uang tunai yang diberikan langsung kepada siswa yang berasal dari keluarga miskin. Siswa yang diberikan BSM yaitu peserta didik yang belajar di SD, SMP, SMA dan SMK baik negeri maupun swasta. Penerima BSM adalah siswa yang telah ditetapkan oleh Kementerian Pendidikan dan Kebudayaan (Kemendikbud) berdasarkan mekanisme yang telah ditetapkan. Berdasarkan buku Petunjuk Teknis (Juknis) BSM tahun 2014, dana BSM digunakan untuk pembelian perlengkapan siswa misalnya buku pelajaran, alat tulis, sepatu dan tas, biaya transportasi siswa ke sekolah, uang saku untuk siswa sekolah. Program BSM dilaksanakan oleh 2 (dua) Kementerian yang berbeda, yaitu Bantuan Siswa Miskin (BSM) bagi sekolah regular yang dilaksanakan oleh Kementerian Pendidikan dan Kebudayaan (Kemendikbud) dan BSM bagi siswa yang bersekolah di Madrasah yang dilaksanakan oleh Kementerian Agama (Kemenag). Sumber dana semua bantuan ini adalah dari APBN.

\subsection{Sistem Pendukung Keputusan}

Sri Eniyati (2011:16) berpendapat "SPK adalah sebuah sistem cerdas yang mengorganisasi informasi untuk membuat keputusan. Pembuatan sistem ini diharapkan mampu membantu menyelesaikan permasalahan yang ada dan sistem ini menggunakan kriteria-kriteria yang ada sehingga bantuan akan diberikan kepada penerima yang paling berhak menerima".

\subsection{Multi-Attribute Decision Making (MADM)}

MADM adalah suatu metode yang digunakan untuk mengevaluasi beberapa kriteria untuk pengambilan keputusan. Inti dari MADM ialah menentukan bobot dari setiap atribut yang kemudian akan dilakukan proses perangkingan. Pada dasarnya, proses MADM dilakukan melalui 3 tahap, yaitu penyusunan komponen - komponen situasi, analisis, dan sintesis informasi (Rudolphi, 2000).

\subsection{Simple Additive Weighting (SAW)}

Metode penjumlahan terbobot, konsep dasar mencari penjumlahan terbobot dari rating kinerja pada setiap alternatif pada semua atribut (Kusumadewi, harjoko, dan Wardoyo. 2006).

$$
r_{i j} \begin{cases}\frac{x_{i j}}{\max _{i} x_{i j}} & \text { Jika j adalah atribut keuntungan (benefit) } \\ \frac{\min _{i} x_{i j}}{x_{i j}} & \text { Jika j adalah atribut biaya (cost) }\end{cases}
$$


Keterangan :

$\mathrm{R}_{\mathrm{ij}} \quad$ : rating kinerja ternormalisasi.

$\operatorname{Max}_{\mathrm{i}}$ : nilai maksimum dari setiap baris dan kolom.

$\mathrm{Min}_{\mathrm{i}}$ : nilai minimum dari setiap baris dan kolom.

$\mathrm{X}_{\mathrm{ij}} \quad$ : baris dan kolom dari matrik.

\section{Perancangan Sistem}

\subsection{Context Diagram}

Menurut Kristanto (2008), "Context Diagram merupakan tingkatan tertinggi dalam diagram aliran data dan hanya memuat satu proses, menunjukkan sistem secara keseluruhan. Proses tersebut diberi nomor nol. Semua entitas eksternal yang ditunjukkan pada diagram kontekas berikut aliran data-aliran data utama menuju dan dari sistem. Diagram tersebut tidak memuat penyimpanan data dan tampak sederhaan untuk diciptakan, begitu entitas-entitas eksternal serta aliran data-aliran data menuju dan dari sistem diketahui menganalisis dari wawancara dengan user dan sebagai hasil analisis dokumen".

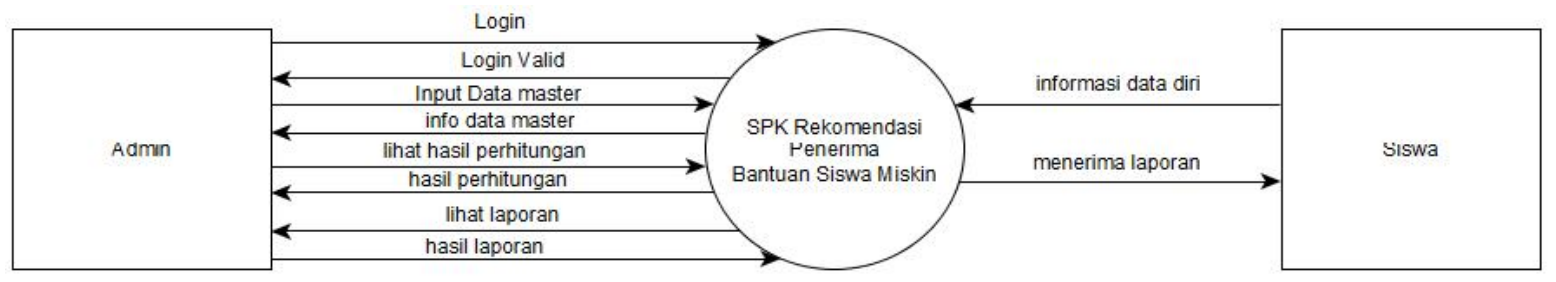

Gambar 2.1 Context Diagram

\subsection{Data Flow Diagram (DFD)}

Kristanto (2008:61), menyatakan bahwa "Data Flow Diagram merupakan suatu model logika data atau proses yang dibuat untuk menggambarkan darimana asal data dan kemana tujuan data yang keluar dari sistem, dimana data disimpan, proses apa yang menghasilkan data tersebut dan interaksi anatara data yang tersimpan dan proses yang dikenakan pada data tersebut".

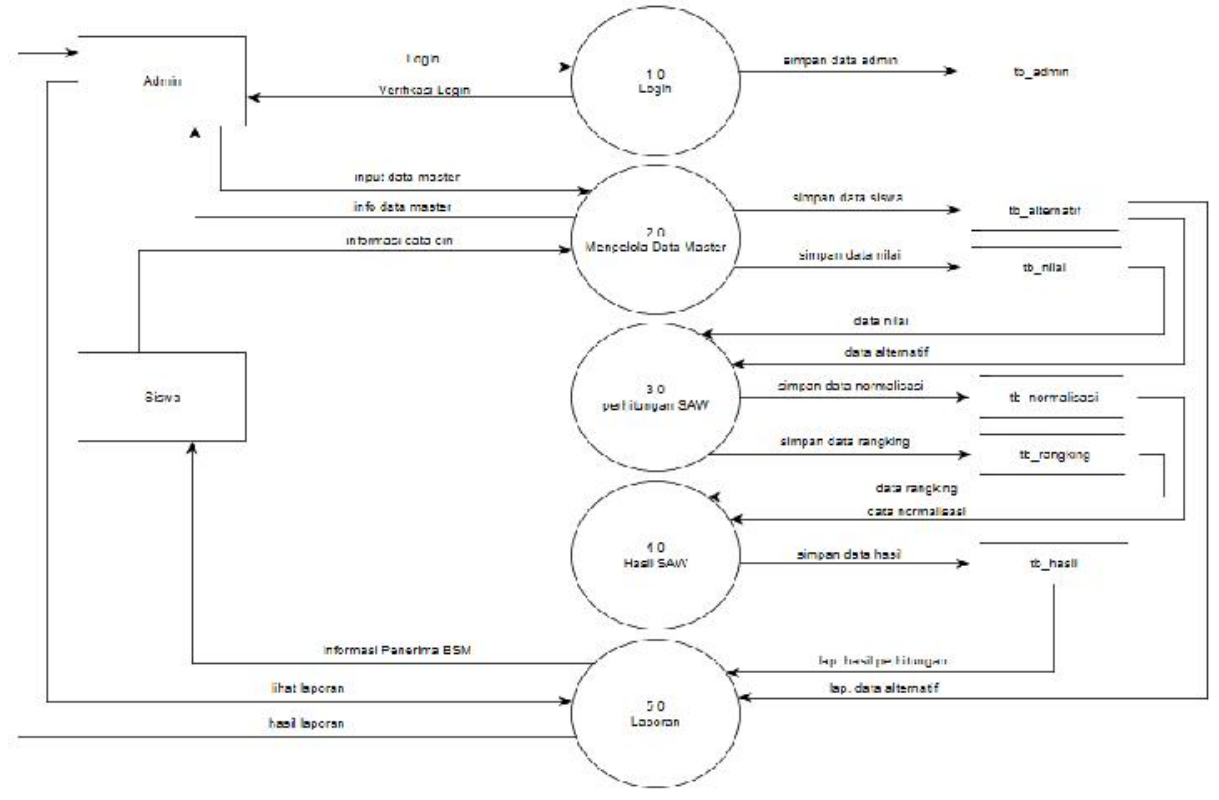

Gambar 3.1 Data Flow Diagram (DFD) 


\subsection{Entity Relationship Diagram (ERD)}

Entity-Relationship adalah salah satu metode pemodelan basis data yang digunakan untuk menghasilkan skema konseptual untuk jenis/model data semantik sistem. Dimana sistem seringkali memiliki basis data relasional, dan ketentuannya bersifat top-down. Diagram untuk menggambarkan model Entity-Relationship ini disebut Entity-Relationship Diagram, ER Diagram, atau ERD (Sutanta, 2011).

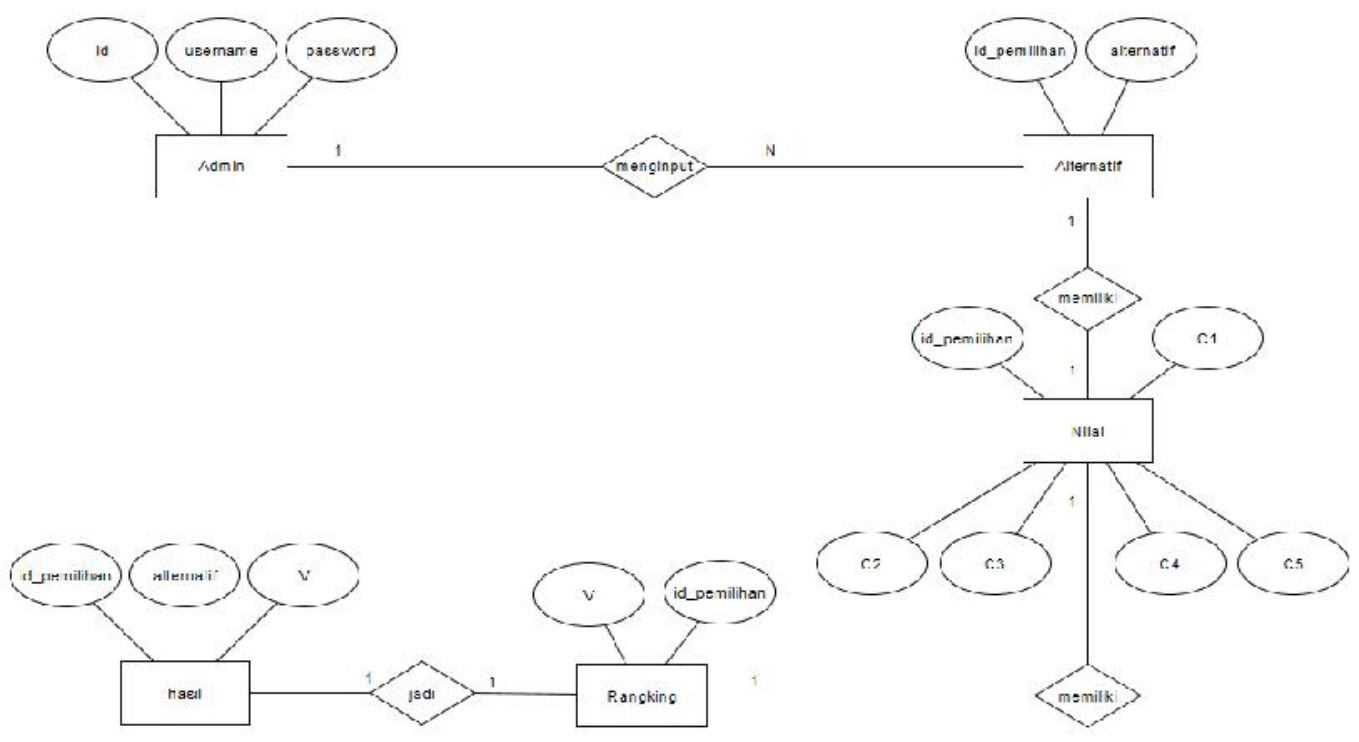

Gambar 3.2 ERD

\section{Implementasi Dan Pembahasan}

\subsection{Form Login}

Form ini dirancang untuk melakukan proses login oleh admin untuk menjalankan aplikasi. Pada tampilan ini perlu melakukan registrasi dengan memasukkan username dan password. Berikut tampilan dari form login :

\section{Login}

Username
Username
Password
Password
Login

Gambar 4.1 Form Login

\subsection{Form Halaman Utama}

Form halaman utama merupakan halaman yang akan ditampilkan pertama jika admin berhasil melakukan login. Berikut tampilan form halaman utama : 


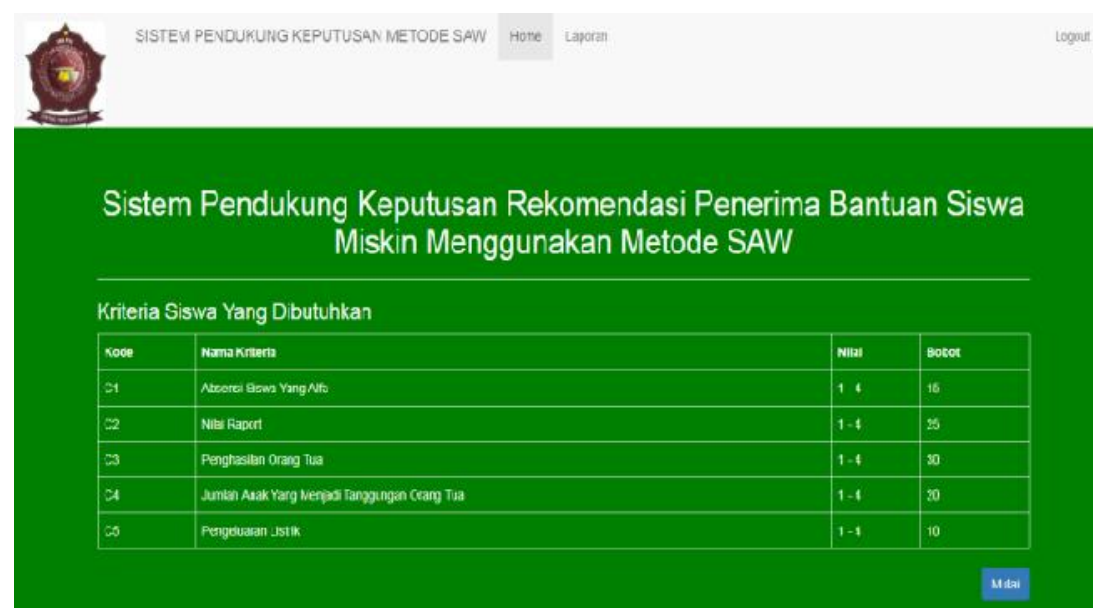

Gambar 4.2 Form Halaman Utama

\subsection{Form Keterangan Kelas}

Form ini dirancang untuk mengetahui siswa kelas berapa. Berikut tampilan dari form keterangan kelas :

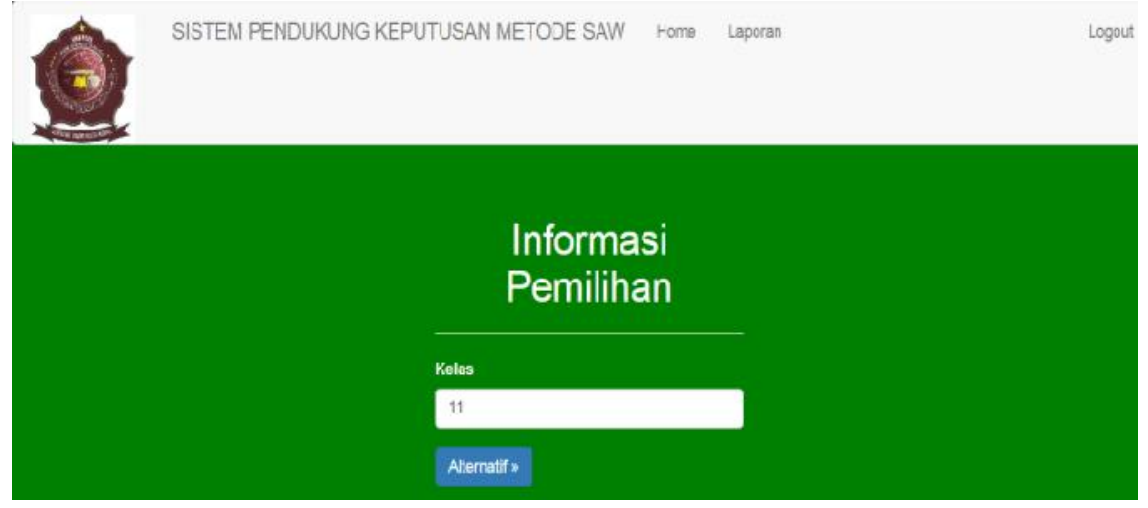

Gambar 4.3 Form Keterangan Kelas

\subsection{Form Input Alternatif}

Form input alternanif dirancang untuk meng-input data alternatif siswa atau nama siswa. Berikut ini merupakan tampilan form input alternatif :

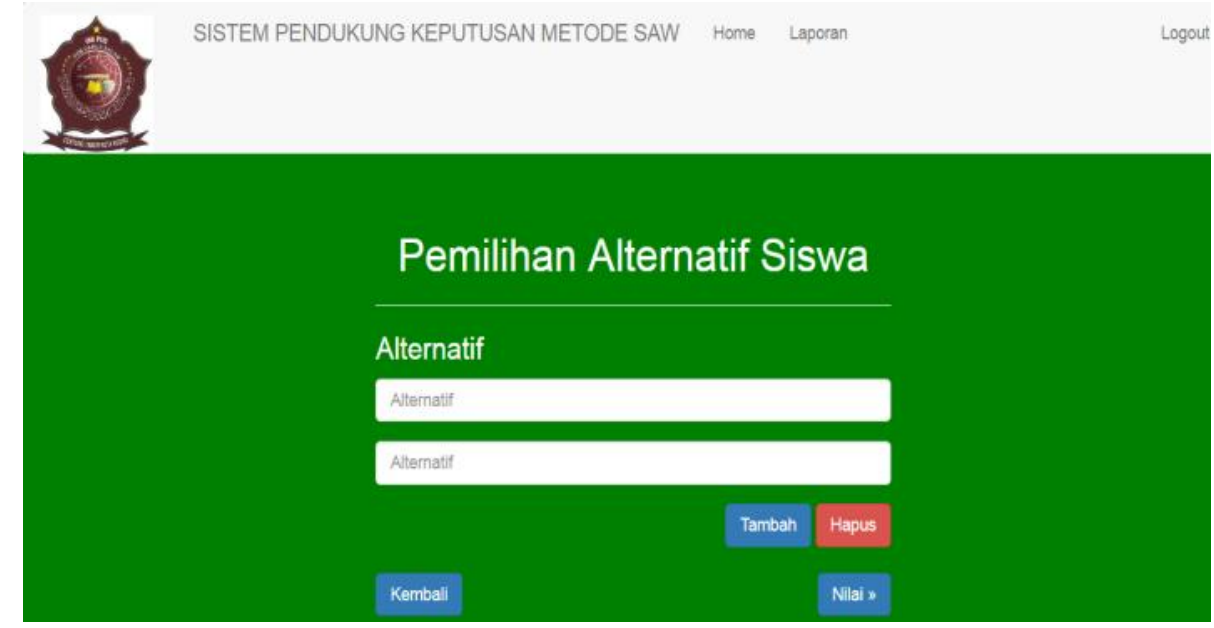

Gambar 4.4 Form Input Alternatif 


\subsection{Form Penilaian}

Form penilaian dirancang untuk menginputkan nilai masing - masing kriteria siswa yang akan dihitung dengan menggunakan metode SAW. Berikut ini merupakan tampilan form penilaian :

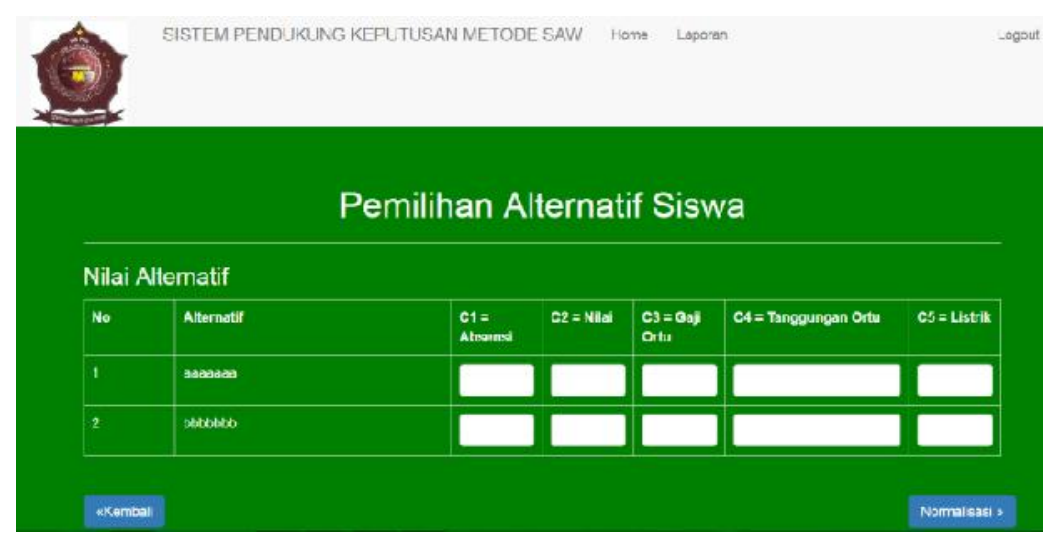

Gambar 4.5 Form Penilaian

\subsection{Form Normalisasi}

Form normalisasi dirancang untuk mengetahui nilai yang didapatkan setelah perhitungan normalisasi. Berikut ini merupakan desain form normalisasi :

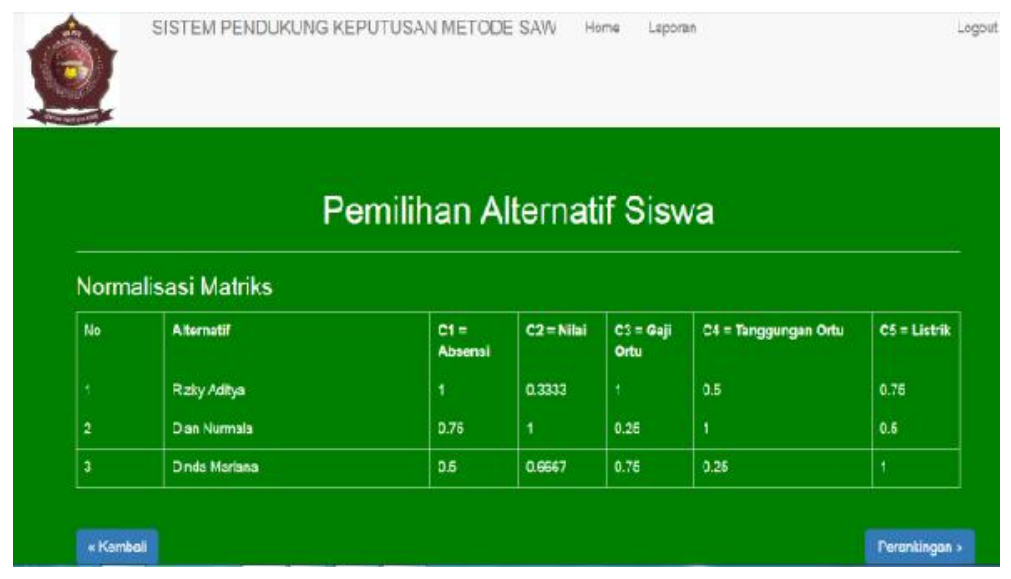

Gambar 4.6 Form Normalisasi

\subsection{Form Perangkingan}

Form perangkingan dirancang untuk mengetahui berapa nilai yang didapatkan di tahap perhitungan perangkingan. Berikut ini merupakan desain form perangkingan :

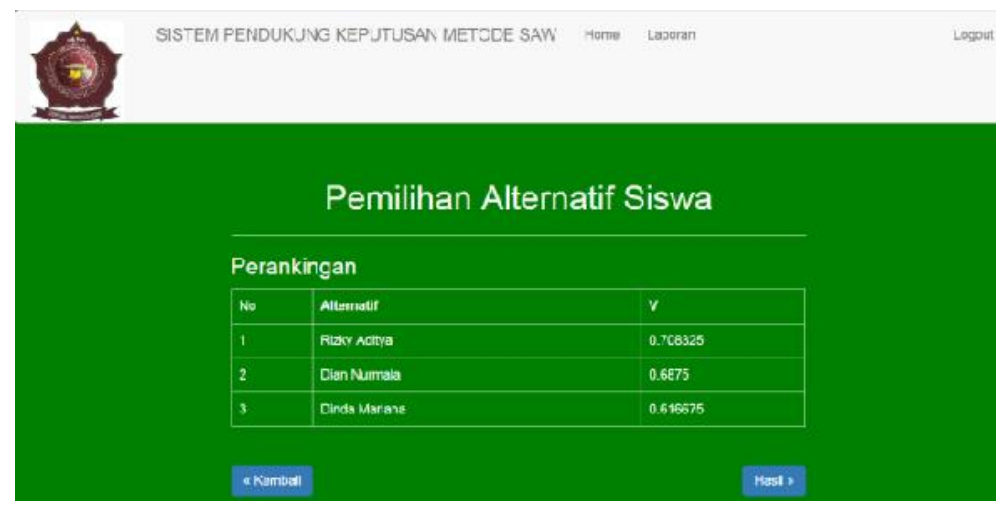

Gambar 4.7 Form Perangkingan 


\subsection{Form Hasil Perangkingan}

Form hasil perangkingan ini dirancang untuk mengetahui nilai akhir perhitungan dan menampilkan saran siswa penerima bantuan. Berikut ini merupakan desain form hasil perangkingan :

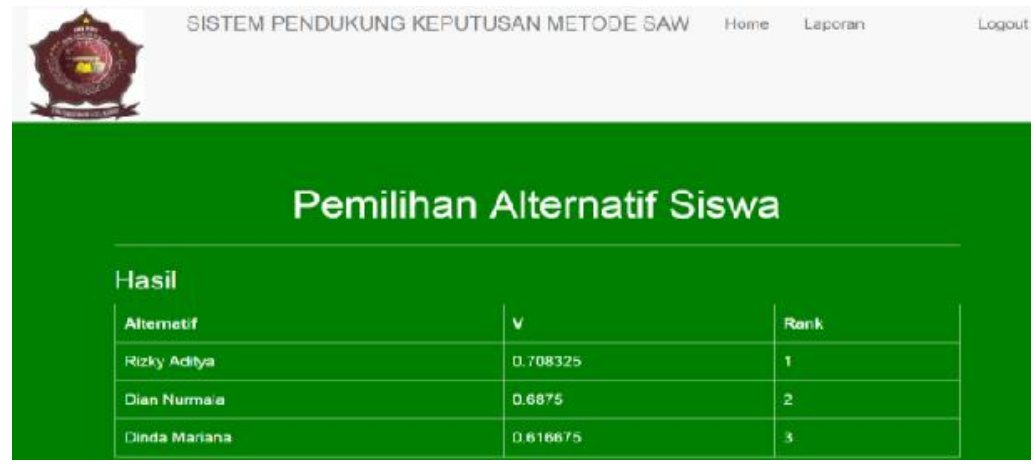

Gambar 4.8 Form Hasil Perangkingan

\subsection{Form Laporan}

Form laporan ini dirancang untuk melihat semua data yang pernah dihitung. Berikut ini merupakan desain form laporan :

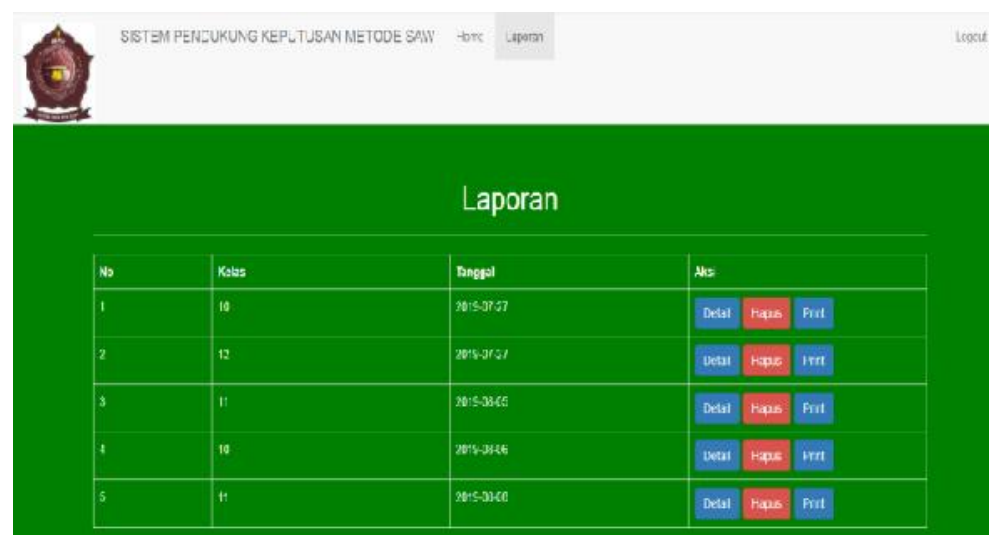

Gambar 4.9 Form Laporan

\subsection{Form Detail Laporan}

Form detail laporan dirancang untuk mengetahui detai dari perhitungan yang pernah diolah. Berikut ini adalah desain form detail laporan :

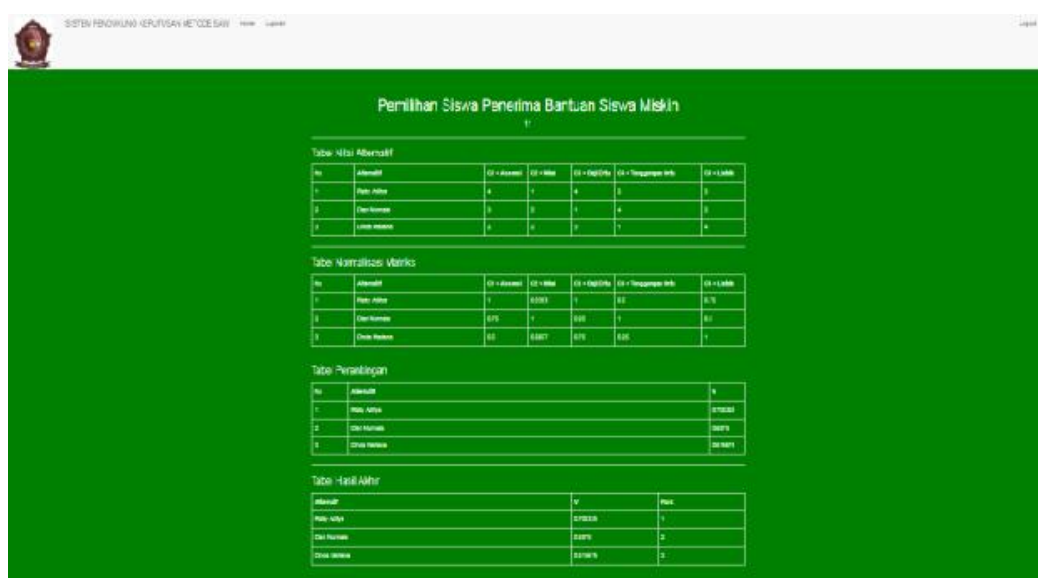

Gambar 4.10 Form Detail Laporan 


\section{Kesimpulan dan Saran}

\subsection{Kesimpulan}

Berdasarkan pembahasan implementasi dan evaluasi dari bab-bab sebelumnya serta teori yang ada, maka dapat ditarik kesimpulan sebagai berikut :

a. Aplikasi SPK yang dibuat dapat memberikan solusi terbaik di dalam penentuan rekomendasi dalam mendukung keputusan penerima bantuan siswa miskin.

b. Sistem yang dibangun dapat mengurangi kesalahan dalam menentukan penerima calon beasiswa.

\subsection{Saran}

Adapun saran yang diberikan untuk perkembangan sistem ini antara lain :

a. Ditunjuknya staff khusus untuk melakukan pembaharuan dan pemeliharaan sistem.

b. Sistem pendukung keputusan penentuan calon penerima bantuan siswa miskin ini perlu dilengkapi dengan metode lain, guna melakukan perbandingan antara metode SAW dengan metode lainnya.

c. Tetap terjaganya koordinasi antar user dalam melakukan penyeleksian bantuan siswa miskin.

\section{References}

[1] Darudin. 2016. Sistem Rekomendasi Penerimaan Beasiswa Menggunakan Metode Simple Additive Weighting SDN 2 Kates. Kediri. Universitas PGRI Kediri.

[2] Eniyati, S. 2011. Perancangan Sistem Pendukung Pengambilan Keputusan Untuk Penerimaan Beasiswa Dengan Metode SAW. Jurnal Teknologi Informasi Dinamik. Vol 16 No 2:171-176.

[3] Khouf, Ridwan Halim. 2017. Sistem Pendukung Keputusan Kelayakan Calon Penerima Bantuan Bedah Rumah Di Kecamatan Sambirejo Dengan Metode Simple Additive Weighting (SAW). Surakarta. Universitas Muhammadiyah Surakarta.

[4] Kusrini. 2007. Konsep Dan Aplikasi Sistem Pendukung Keputusan. Yogyakarta: Andi.

[5] Kusumadewi, Hartati, S., Harjoko, A., \& Wardoyo, R. 2006. Fuzzy Multiple - Attribute Decision Making. Yogyakarta: Graha Ilmu.

[6] Kristanto, Andri. 2008. Perancangan sistem Informasi dan Aplikasinya. Yogyakarta: Gaya Media.

[7] Nofriansyah, Dicky. 2014. Konsep Data Mining Vs Sistem Pendukung Keputusan. Yogyakarta: Deepublish.

[8] Sugiyono. 2017. Metode Penelitian Kuantitaif Kualitatif Dan R\&D. Bandung: AlfaBeta.

[9] Sukamto, A Rosa dan M Shalahudin. 2014. Rekayasa Perangkat Lunak. Bandung: Informatika.

[10] Susanto, A. 2000. Sistem Informasi Manajemen: Konsep \& Pengembangannya. Bandung: Lingga Jaya.

[11] Sutanta, E. 2011. Sistem Basis Data : Konsep Penerapan Dalam Sistem Informasi Manajemen. Yogyakarta: Andi Offset.

[12] Turban, E., Aronson, J., \& Liang, T.P. 2008. Decision Support System and Intelligent System. Yogyakarta: Andi.

[13] Utomo, Didik Prasetyo. 2017. Sistem Pendukung Keputusan Penentuan Bantuan Khusus Siswa Miskin Dengan Metode Analytical Hierarchy Process (AHP) Pada SMA Negeri 1 Plosoklaten. Kediri. Universitas PGRI Kediri.

[14] Wibisono, Darmawan. 2003. Riset Bisnis Panduan Bagi Praktisi \& Akademisi. Jakarta: Gramedia.

[15] http://edukasi.kompas.com/read/2012/02/29/09553124/BSM.Belum.Menyentuh.Seluruh.Siswa. Miskin 
[16] S. W. Mudjanarko, S. Winardi, and A. D. Limantara, "Pemanfaatan internet of things (iot) sebagai solusi manejemen transportasi kendaraan sepeda motor," Pros. Semin. Nas. Apl. Teknol. Prasarana Wil. X, no. August, 2017.

[17] A. D. Triono et al., "Utilization of Pedestrian Movement on the Sidewalk as a Source of Electric Power for Lighting Using Piezoelectric Censors," in 2018 3rd IEEE International Conference on Intelligent Transportation Engineering, ICITE 2018, 2018.

[18] A. D. Limantara, L. D. Krisnawati, S. Winardi, and S. W. Mudjanarko, "Solusi Pengawasan Kebijakan Mengatasi Kemacetan Jalan dan Parkir Kota Berbasis Internet Cerdas," Semin. Nas. Teknol. dan Rekayasa Inf., no. November, pp. 1-6, 2017.

[19] A. D. Limantara, S. Winarto, and S. W. Mudjanarko, "Sistem Pakar Pemilihan Model Perbaikan Perkerasan Lentur berdasarkan Indeks Kondisi Perkerasan (Pci)," Semin. Nas. dan Teknol. Fak. Tek. Universtas Muhammadiyah Surakarta, no. November, pp. 1-2, 2017.

[20] A. D. Limantara, Y. Cahyo, S. Purnomo, and S. W. Mudjanarko, "Pemodelan Sistem Pelacakan LOT Parkir Kosong Berbasis Sensor Ultrasonic Dan Internet Of Things ( IOT ) Pada Lahan Parkir Diluar Jalan,” Semin. Nas. Sains dan Teknol., vol. 1, no. 2, pp. 1-10, 2017.

[21] A. Alimudin, A. Z. Falani, S. W. Mudjanarko, and A. D. Limantara, "Analisis Pengaruh Penerapan Perspektif Balanced Scorecard Terhadap Peningkatan Kinerja UMKM," Ekonika J. Ekon. Univ. kadiri, vol. 4, no. 1, p. 1, 2019. 